\title{
A MODIFIED ARCAN TEST FOR MIXED-MODE LOADING OF BOLTED JOINTS IN COMPOSITE STRUCTURES
}

\author{
Garth M Pearce ${ }^{1}$, Congyuan Tao ${ }^{1}$, Yong H E Quek ${ }^{1}$, \\ ${ }^{1}$ School of Mechanical and Manufacturing Engineering, UNSW, NSW, Australia.
}

Keywords: Bolted Joints, Composite Structures, ARCAN Testing

\begin{abstract}
A novel modified Arcan test rig has been developed for testing the combined loading performance of bolted joints in composite laminates. The fixture was designed to complement existing bearing test standards (ASTM D5961) and pull-through test standards (ASTM D7332). A mixed-mode loading fixture for bolted joints in composite laminates fills a crucial niche after it was identified that interactions between pull-through and bearing failure modes can potentially reduce the overall joint performance and lead to anti-conservative designs.

The test fixture was benchmarked against ASTM standards and was found to reliably reproduce pull-through failure behaviour observed during D7332 (Proc. B) testing. Further work is underway to benchmark the new rig against D5961 (Proc. C).

A test program is reported in which bolted joint specimens were loaded at various mixed-mode ratios between pure bearing and pure pull-through. It was found that the initial failure load joint well predicted by a quadratic mode-mixing rule. Ultimate failure load however, was considerably overpredicted by a quadratic mode-mixing rule which could lead to anti-conservative predictions, particularly for dynamic systems in which joints completely fail.

Based on the success of the preliminary testing, there is a strong case for further development and benchmarking of the new test fixture. There is scope for this fixture to be added to the suit of accepted test standards for bolted joints in composite structures.
\end{abstract}

\section{INTRODUCTION}

Composite structures are predominantly mechanically fastened. Despite the associated reduction in mechanical efficiency associated with drilling and fastening structures, bolted joints still offer a level of reliability which is not attainable with bonded joints. It is critical that failure of bolted joints in composite structures is well characterised, and can be predicted, to allow for more efficient structural design and shorter product development cycles.

To date, most standardised mechanical testing of bolted joints in composites is conducted using well-established bearing (ASTM D5961) [1] and pull-through (ASTM D7332) [2] tests. The standard tests fail to capture critical interactions between the different joint failure modes, especially the interaction between bearing and pull-through failure [3]. There are many critical load states in composite airframes in which joints are simultaneously subjected to significant bearing (shear) and pull-through (tensile) loads. Heimbs et al. [4] demonstrated that mixed mode failures are present in many, if not most, bolted joint configurations. It is possible, probably likely [3], that the mixed-mode failure load is lower than both the bearing and pull-through design loads individually. It is therefore critical that combined (mix-mode) failure of bolted joints can be investigated in a rigorous as repeatable way.

This paper presents a novel test fixture, inspired by the classic ARCAN rig, for combined loading of bolted composite joints. The test fixture allows a composite bolted joint specimen to be exposed to a range of loading configurations including pure pull-through, pure bearing, or a combination of the two. The results of two test programs are presented; one using a woven carbon fibre fabric composite (IM7/977-3) laminate and one using a unidirectional carbon fibre composite (T700/VTM264). 


\section{ARCAN TEST FIXTURE}

\subsection{Design Constraints}

The classic ARCAN test [5] has been used to characterise mixed-mode failure of composite laminates [6]. This fixture has inspired many similar fixtures for mixed-mode mechanical testing of, among others, adhesives [7] and mechanical fasteners [8].

As outlined in the introduction, there was a need to investigate the failure of bolted joints in composite laminates under a combination of pull-through and bearing loads; a new test fixture was required. For the new fixture, several design constraints were imposed to limit complexity:

- Only single-fastener tests would be considered.

- The same specimen configuration would be used for all loading conditions (pull-through, bearing and combined).

- The same specimen clamping conditions would be used for all loading configurations.

- The test would be design to consider localised failure only (bearing, pull-through, fastener failures). Joint failures related to fastener spacing and location would be ignored (net-tension failure, shear-out failure).

- In order to achieve similar loading conditions between pull-through and bearing cases, only one laminate would be included in the test. The other side of the fastener would be connected directly to the test fixtures (similar to ASTM D5961 - Procedure C)

\subsection{Fixture Geometry}

An ARCAN-style configuration for the test was chosen for the ability to apply multiple load cases with the same specimen configuration. A design for the bolted joint ARCAN test fixture [9] is shown in Figure 1. The central section, including the two semi-circular plates, can be rotated relative to the vertical loading axis to apply combined loading conditions. The loading holes are aligned radially with a single datum point, as shown in Figure 2.

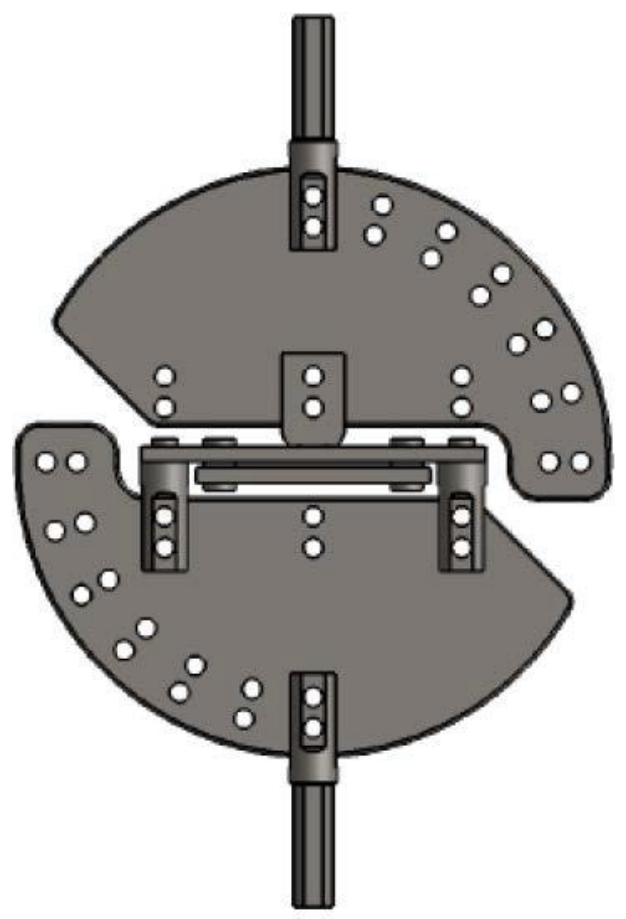

Figure 1: Bolted joint ARCAN test fixture design

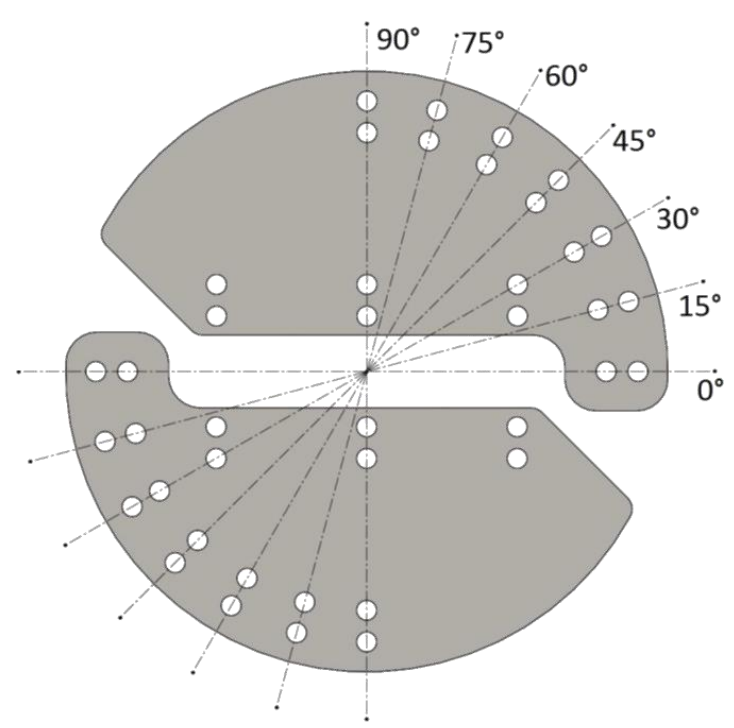

Figure 2: ARCAN plate loading directions 


\subsection{Combined Loading}

It is natural to assign an angular coordinate to the combined loading condition. The reference configuration (bearing) is referred to as a $0^{\circ}$ test and the pull-through condition is referred to as a $90^{\circ}$ test. Five combined loading configurations are spaced at $15^{\circ}$ intervals, as shown in Figure 2.

\subsection{Specimen Configuration}

The test specimens were square carbon fibre composite plates with 100x100mm external dimensions. The thickness of the specimen was dependent on the study, and is described later. The test fixture was designed to accommodate specimens of a range of thicknesses, without modification.

A central hole was drilled in each specimen using a one-shot drill-reamer. The hole accommodated a central bolt which was used to fasten the composite plate to a steel loading plate. A cross-section of the assembled specimen is shown in Figure 3. The specimen was aligned in the fixture such that the ARCAN datum aligned with the intersection of the top specimen face and the central axis of the bolt, as shown.

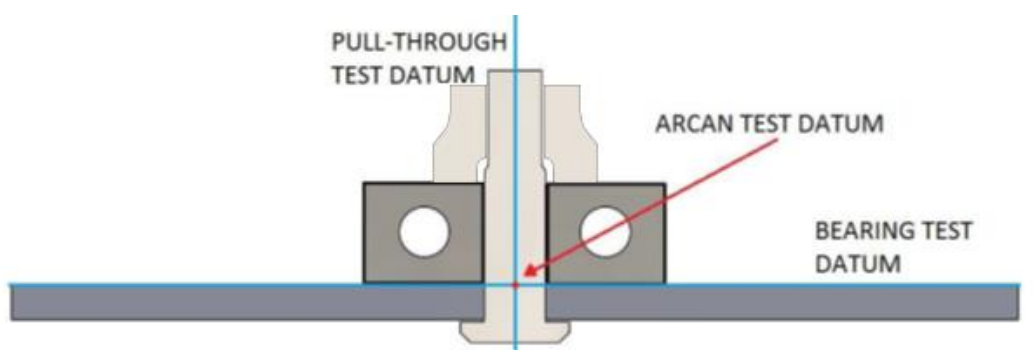

Figure 3: Assembled bolted joint specimen for ARCAN testing

All results reported in this paper share the following common parameters:

- Specimen hole diameter: $6.35 \mathrm{~mm}(0.25 ")$

- Bolt specification: Hi-Lok HL 1012-8-8 (see Figure 4)

○ Diameter: $6.35 \mathrm{~mm}$

- Material: Ti-6Al-4V

○ Head: Protruding

- Collar specification: Hi-Lok HL198V8 (see Figure 4)

- Pretorque: $10 \mathrm{Nm}$

\subsection{Clamping and Assembly}

The specimen was clamped between two $10 \mathrm{~mm}$ steel plates with an internal hole diameter of $60 \mathrm{~mm}$ (Figure 5).

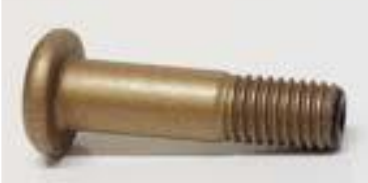

(a)

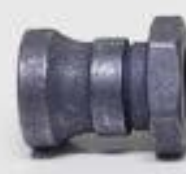

(b)

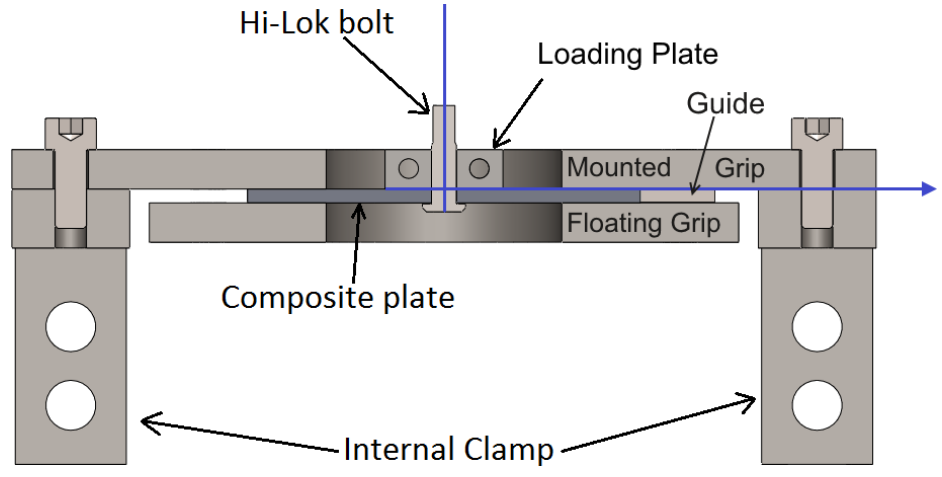

Figure 5: Specimen clamping assembly
Figure 4: Hi-Lok fastener: (a) HL 1012-8-8 pin and (b) HL 198V8 collar 
A guide plate provided a datum for the specimen and restricted specimen motion in the $0^{\circ}$ (bearing) direction. The two plates where then pinned to one half of the ARCAN fixture. The loading plate was assembled to the other half of the ARCAN fixture. A schematic of the full assembly is shown in Figure 6.

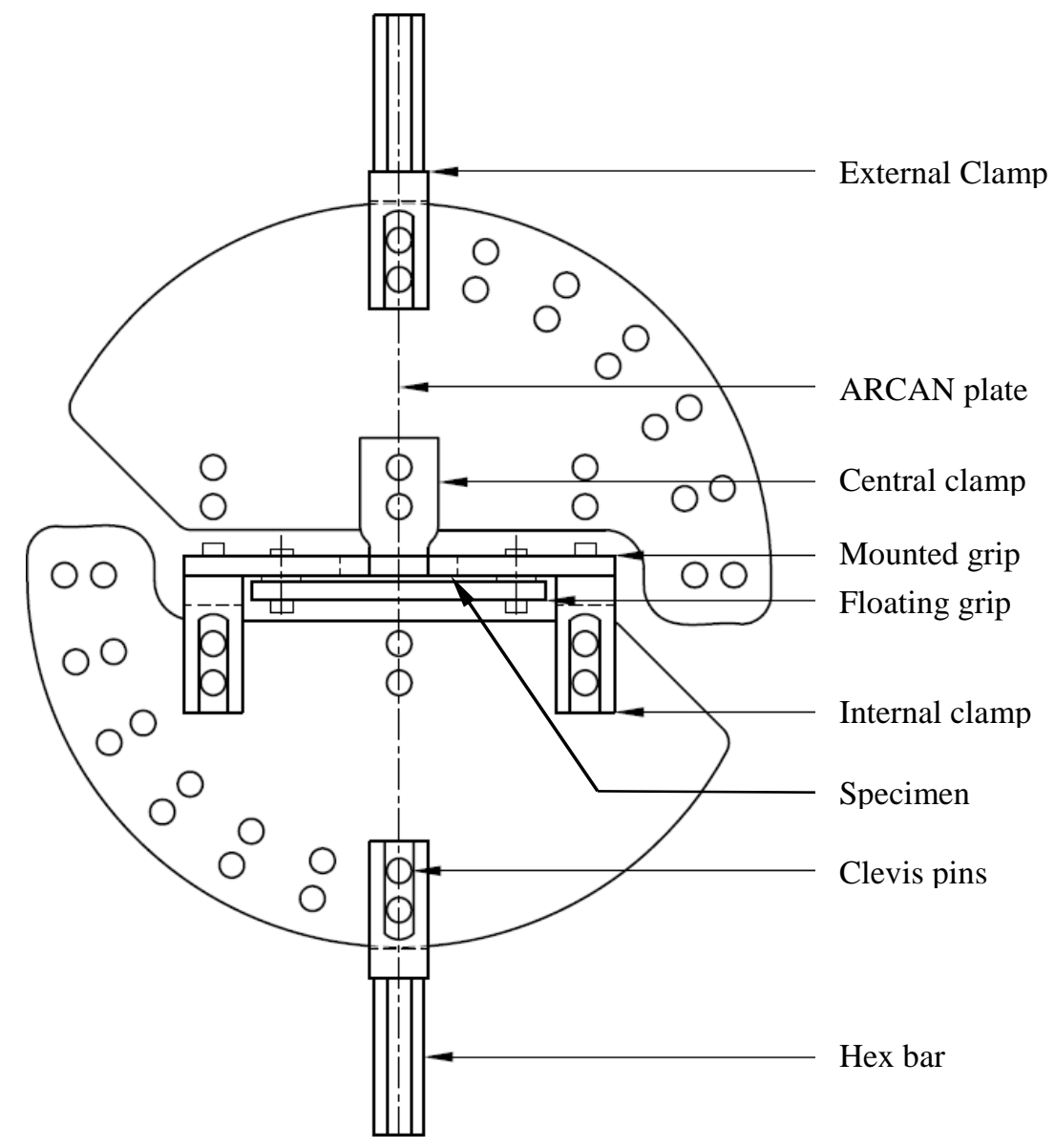

Figure 6: Full bolted joint ARCAN assembly

The physical assembly is shown in Figure 7. Three different loading configurations are shown.

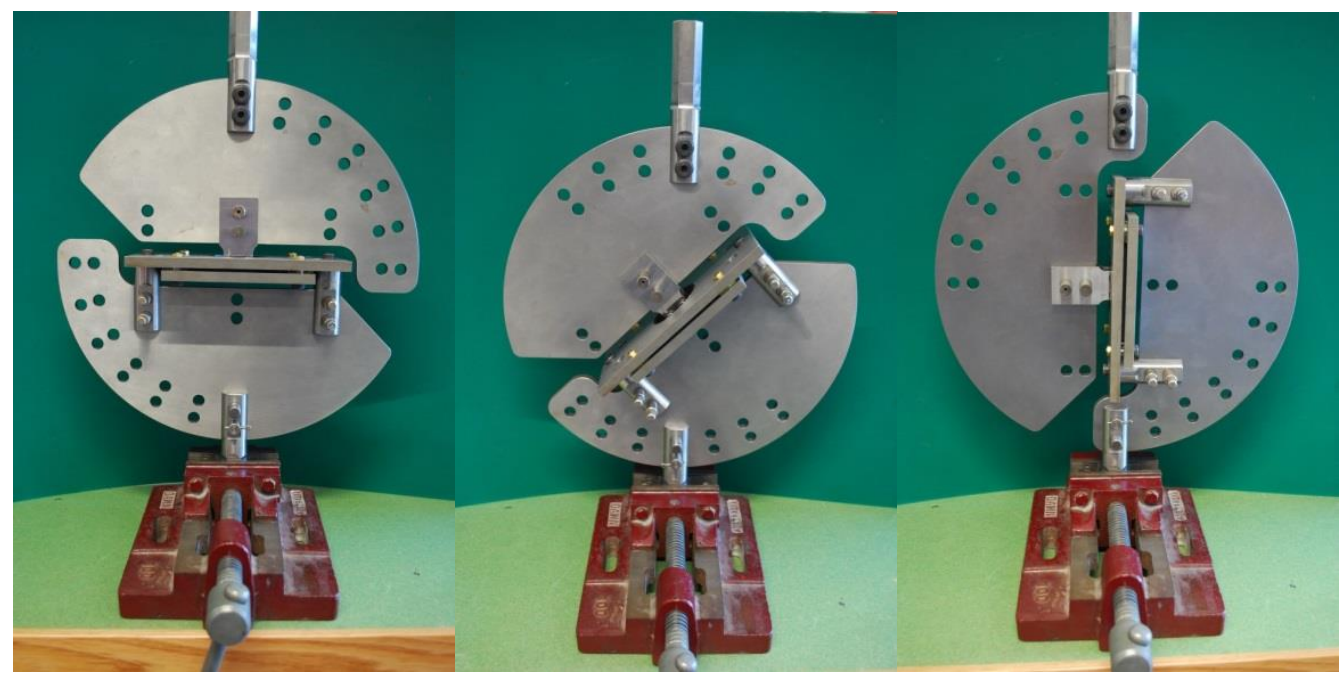

Figure 7: Novel ARCAN bolted joint fixture pictured in pull-through (left), combined loading (centre) and bearing (right) configurations 


\section{EXPERIMENTAL METHODOLOGY}

\subsection{Fabric Composite Study}

This study investigated a prepreg fabric composite laminate (IM7/CYCOM977-3, 5 Harness Satin). Specimens were taken from a $16 \mathrm{ply}, 600 \times 600 \mathrm{~mm}$ plate with a stacking sequence of $\left[[ \pm 45 /(0 / 90)]_{\mathrm{s}}\right]_{4}$. The average cured specimen thickness was $3.32 \mathrm{~mm}$ which satisfied the thickness requirements of ASTM D7332 and D5961. Eighteen 100x100mm specimens were cut using a waterjet cutter.

The specimens were tested at various loading angles, as described by the test matrix in Table 1 .

Table 1: Test matrix for study of fabric composite specimens

\begin{tabular}{|c|c|}
\hline Test & Number of specimens \\
\hline $0^{\circ}$ (Bearing) & 2 \\
\hline $15^{\circ}$ & 2 \\
\hline $30^{\circ}$ & 3 \\
\hline $45^{\circ}$ & 2 \\
\hline $60^{\circ}$ & 2 \\
\hline $75^{\circ}$ & 3 \\
\hline $90^{\circ}$ (Pull-through) & 3 \\
\hline
\end{tabular}

\subsection{UD Study}

This study investigated a prepreg UD tape laminate (T700/VTM264). Specimens were taken from two 16 ply, $400 \times 400 \mathrm{~mm}$ plates with stacking sequence $[ \pm 45 / 0 / 90]_{2 s}$. The averaged specimen thickness was $3.38 \mathrm{~mm}$. A total of 15 specimens were cut from the panels using a diamond wheel.

The specimens were tested at various loading angles, as described by the test matrix in Table 2 . In order to benchmark the test results against existing ASTM standards, four specimens were tested in the ASTM D5961 (Procedure B) configuration and four were tested according to D7332 (Procedure B). The apparatus for the D7332 test is shown in Figure 8.

Table 2: Test matrix for study of UD composite specimens

\begin{tabular}{|c|c|}
\hline Test & Number of specimens \\
\hline $0^{\circ}$ (Bearing) & 3 \\
\hline $45^{\circ}$ & 2 \\
\hline $90^{\circ}$ (Pull-through) & 2 \\
\hline ASTM D5961-B & 4 \\
\hline ASTM D7332-B & 4 \\
\hline
\end{tabular}

\subsection{Testing Parameters and Data Acquisition}

For all ARCAN and D5961 experiments, tensile load was applied using a 500kN servo-hydraulic INSTRON 8804 universal testing machine. Load data was acquired from a 500kN load cell.

For D7332 experiments, load was applied using a dual column $50 \mathrm{kN}$ electro-mechanical INSTRON 3369. Load data was acquired from a $50 \mathrm{kN}$ load cell.

In all tests, the cross-head was displaced at $1 \mathrm{~mm} / \mathrm{min}$. Cross-head displacement was used to determine the relative joint deflection in the absence of a direct measurement system for the ARCAN fixture. Dial gauges were used to measure the deflection directly for some tests but were too cumbersome to use generally. A comparison of the dial gauge and cross-head results indicated that some slack existed in all fixtures under low loads. Once the load exceeded $6 \mathrm{kN}$, however, the crosshead and dial gauges were in 1:1 agreement; indicating that the fixture and testing machine were far stiffer than the specimen. Deflection axes in the results were adjusted to remove the initial fixture slack, as described later. 


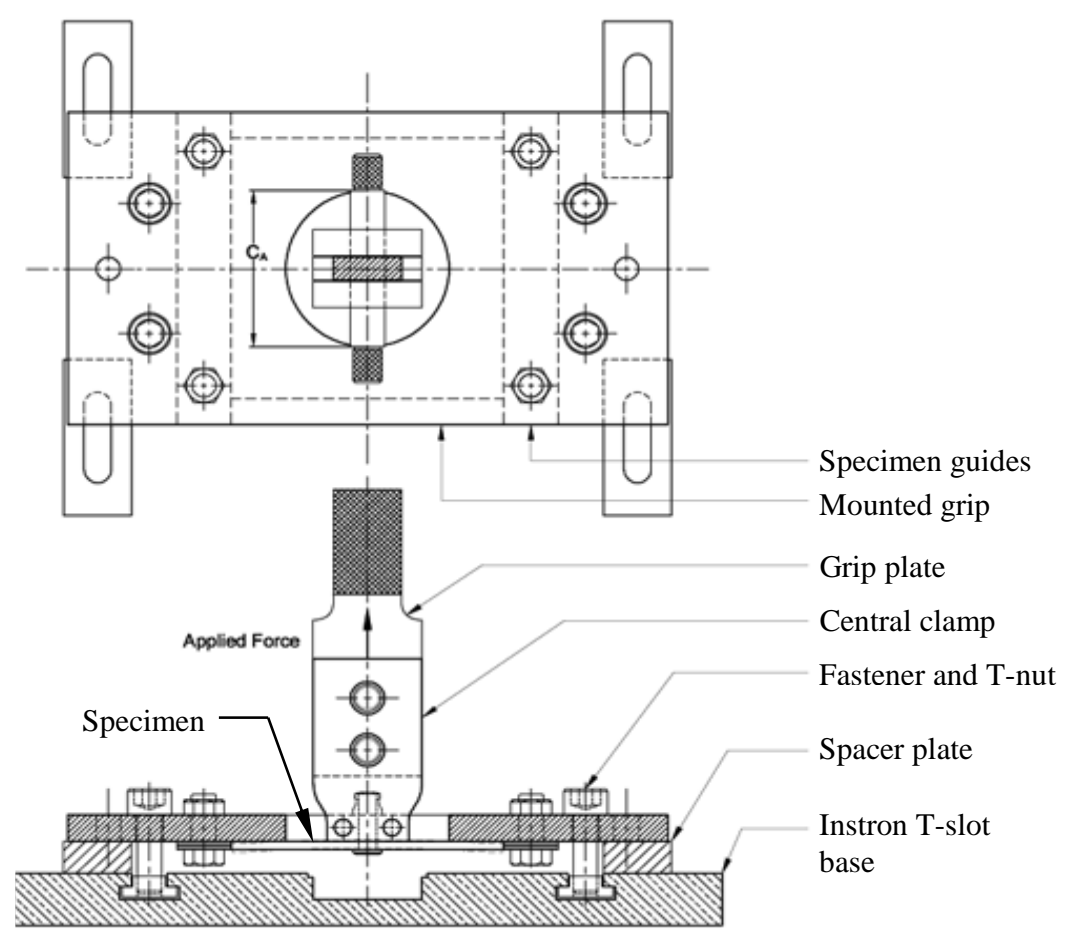

Figure 8: ASTM D7332 test fixture using the grip plate from the ARCAN rig

\section{RESULTS}

\subsection{Results processing}

As described above, cross-head displacement was used as a displacement measure for the test results. The load-displacement results were processed to remove the effect of slack in the test rig. The linear region of the load curve was extrapolated, as shown in Figure 9. The displacement origin of all results presented here was adjusted such that the $\mathrm{x}$-intercept of the linear fit intercepted the origin.

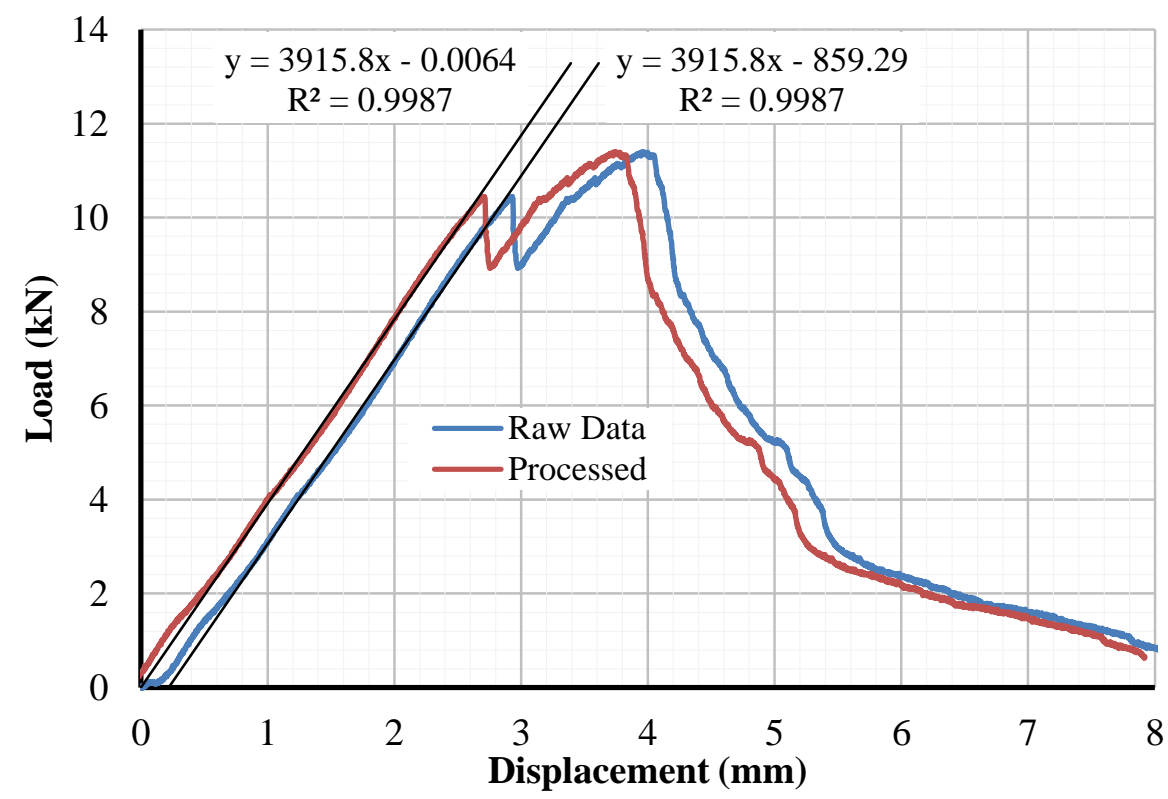

Figure 9: Displacement correction applied to all test data 


\subsection{Fabric Composite Study}

This study investigated fabric composite specimens loaded at various combined loading angles. Sample load-displacement results from each load angle are shown in Figure 10.

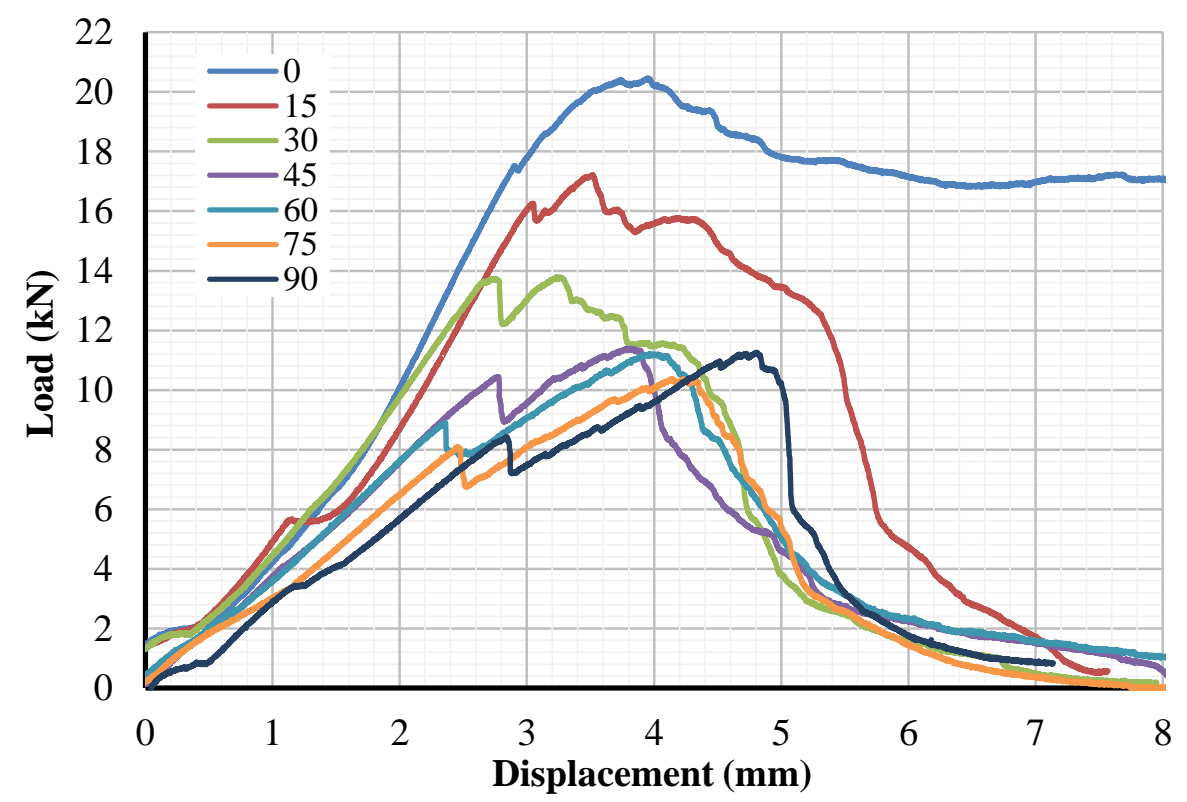

Figure 10: ARCAN test data for IM7/977-3 specimens (one sample at each angle)

Upon inspection, the majority of the results aligned with the typical behaviour expected for ASTM D7332 specimens: Initial linear region including some sub-critical damage, significant failure event with an associated load drop, a peak load which exceeded the initial failure load, and finally a rupture event or very significant load drop.

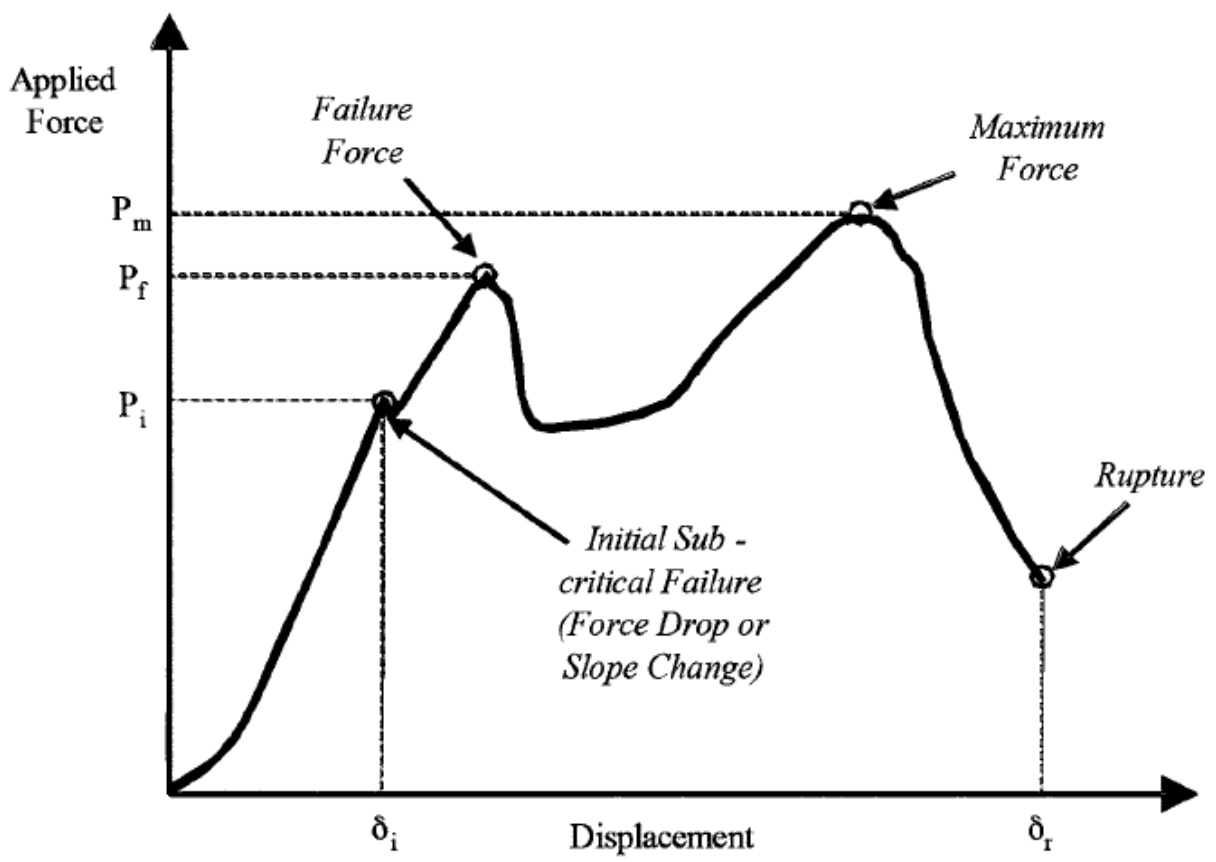

Figure 11: Characteristic failure curve for ASTM D7332 specimens [2] 
The failure load and maximum load were extracted for every specimen. Using the loading angle, an in-plane component and an out-of-plane (normal) component were projected for both load levels. The full data set is shown in Figure 12.

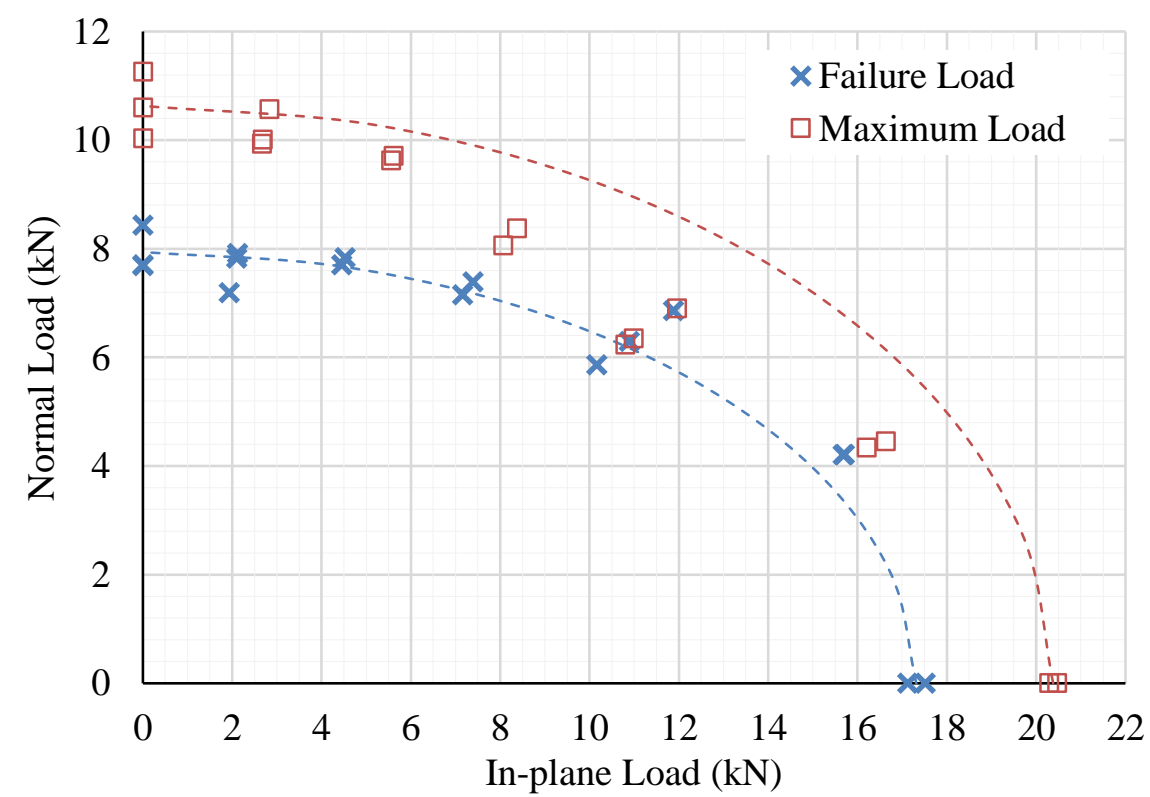

Figure 12: Initial failure load (blue) and peak failure load (red) as a function of in-plane bearing load and normal pull-through loads

It was found that, to a first approximation, the failure load of the joints was well predicted by a quadratic function, as shown in Equation 1.

$$
\left(\frac{f_{n}}{F_{P T}}\right)^{2}+\left(\frac{f_{s}}{F_{B}}\right)^{2}=1
$$

where $f_{n}$ and $f_{s}$ are the applied normal and shear forces and $F_{P T}$ and $F_{B}$ are the measured critical pull-through and bearing loads, respectively. The equation is represented as a dashed blue line in Figure 12. It was also found that the maximum load was considerably over-predicted by a quadratic relationship; indicating that there is interaction between the bearing and pull-through damage.

External specimen damage was investigated. A selection of cases is shown in Table 3. Damage for combined loading specimens appeared to be intermediate between bearing and pull-through, with damage features of both idealised cases. Further work is underway to investigate the damage characteristics in more detail.

\subsection{UD Study}

The test fixture was benchmarked against accepted ASTM standard test methods. ARCAN bearing tests are compared with ASTM D5961 (Proc. B) in Figure 13. Similarly, ARCAN pull-through tests are compared to ASTM D7332 (Proc. B) in Figure 14.

There is a significant difference between the loading conditions of ASTM D5961 (Proc. B) and the new ARCAN fixture, hence the load-displacement curves are not directly comparable. Despite the differences, similar maximum loads were attained. A more apt comparison for benchmarking purposes is ASTM D5961 (Proc. C), which includes a one-sided joint. This study is underway.

There is a subtle difference in the specimen clamping between the new ARCAN bearing test and ASTM D7332 (Proc. B); the ARCAN case is fully clamped, as opposed to simply supported at the hole edge in the ASTM case. The clamping differences result in an initial modulus difference, yet after some sub-critical damage, the specimens behave nearly identically. 
Table 3: External specimen damage for various loading angles (Bearing side of hole is toward the top of the page)

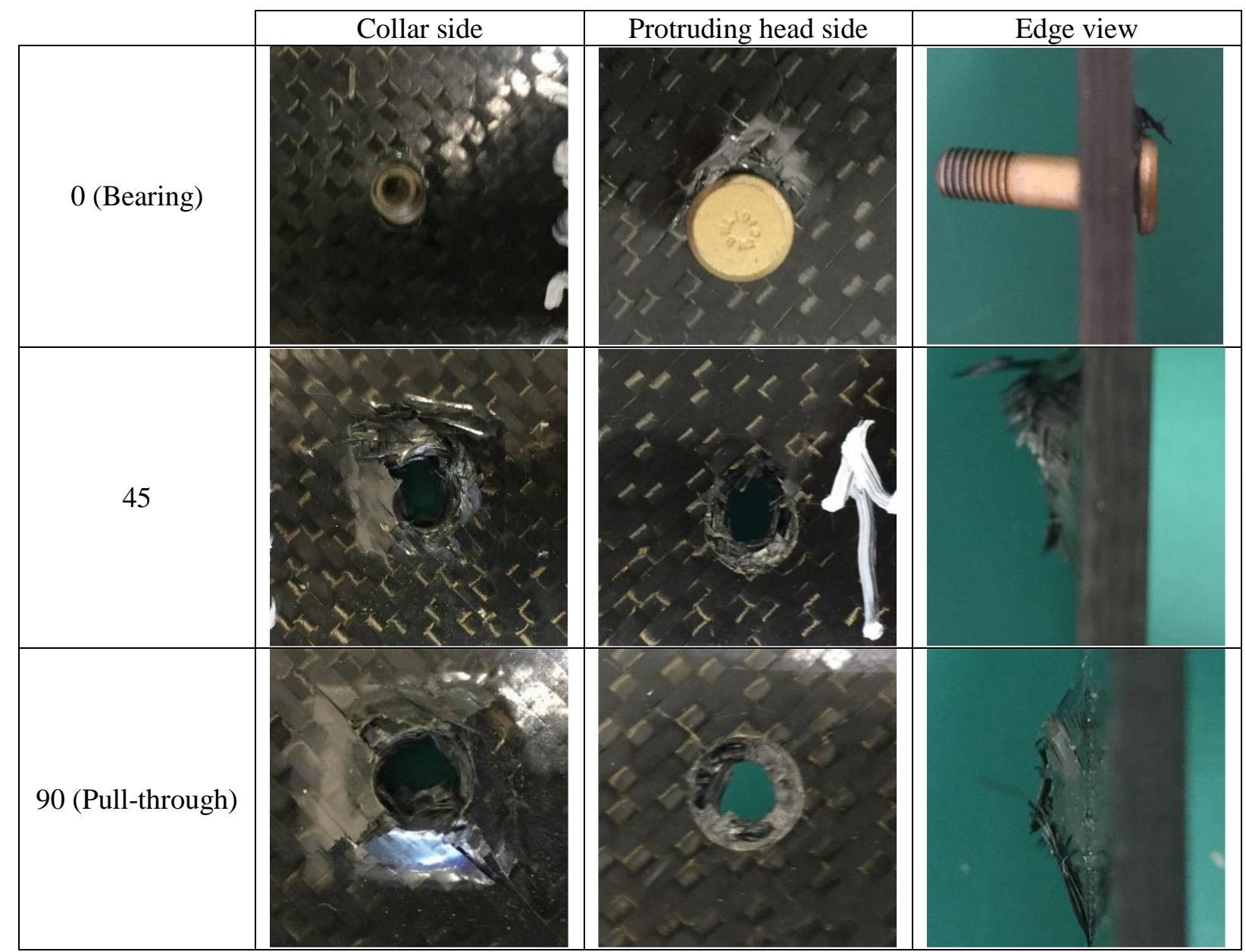

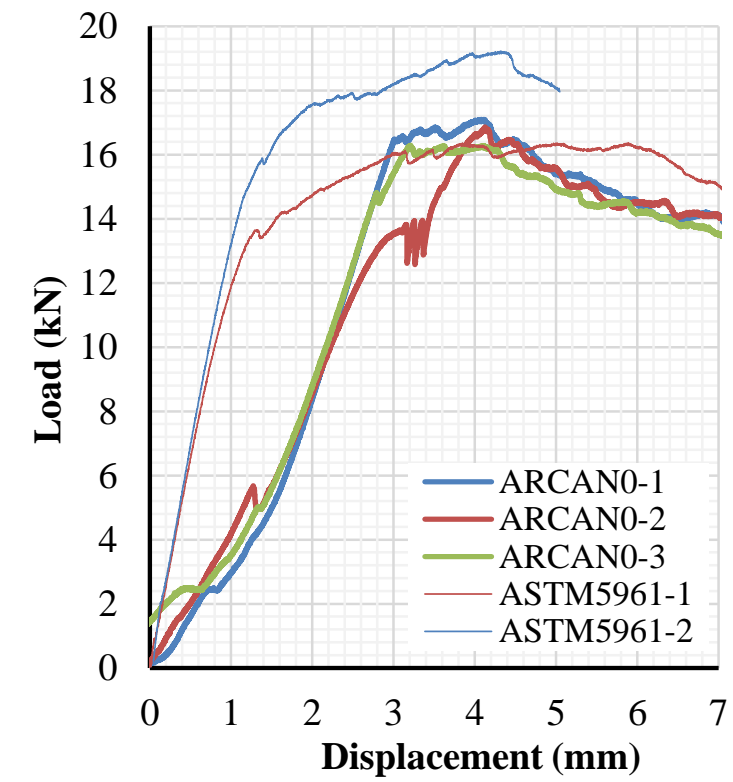

Figure 13: ARCAN $0{ }^{\circ}$ tests vs ASTM D5961-B

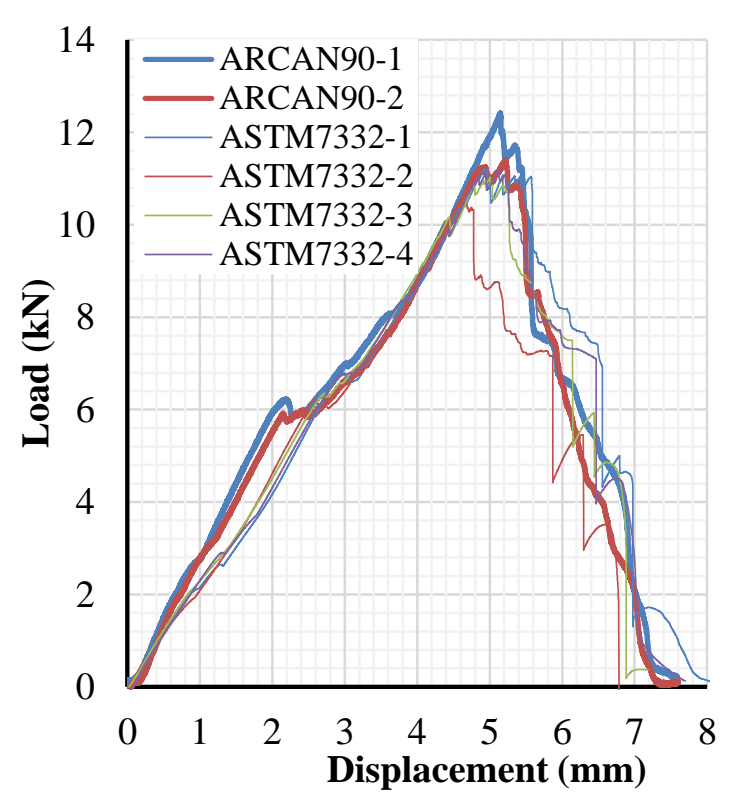

Figure 14: ARCAN $90^{\circ}$ tests vs ASTM D7332-B 
For comparison with Figure 10, a bearing, combined and pull-through result are shown in Figure 15.

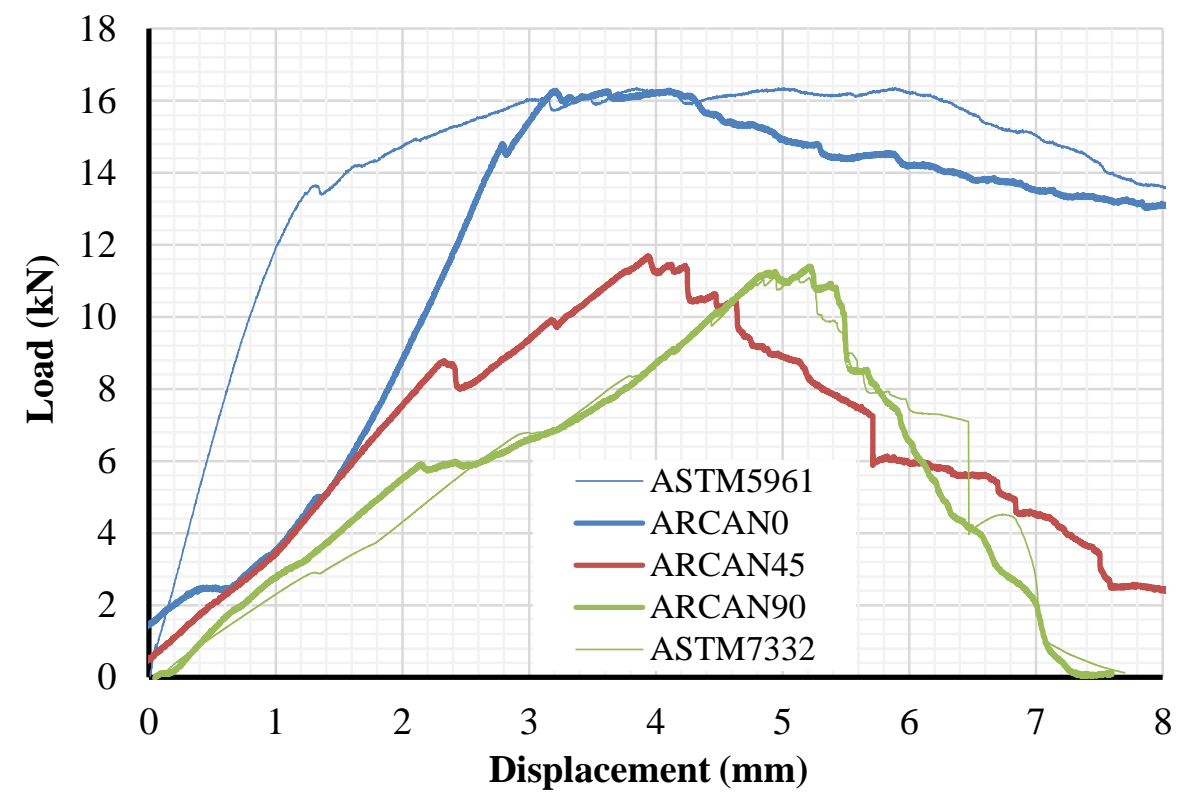

Figure 15: ARCAN test data for T700/VTM264 specimens (one sample at each angle)

\section{DISCUSSION AND CONCLUSIONS}

A novel test fixture has been proposed to investigate combined loading of bolted joints in composite structures, based on an ARCAN-style testing configuration. The fixture does not supersede the existing test standards (ASTM D5961 and D7332), but has been designed to be a compatible test configuration. A major advantage of the proposed test is the direct comparison between bearing and pull-through tests with an identical specimen configuration.

The fixture was benchmarked against existing ASTM testing standards in the bearing and pullthrough configuration. It was shown that in the pull-through configuration, very similar results were achieved to ASTM D7332 (Proc. B). Agreement between the ARCAN bearing configuration and ASTM D5961 (Proc. B) was less direct, as specimen configurations differ significantly. Work is underway to compare the current results with those obtained from ASTM D5961 (Proc. C), which is a more direct test comparison.

A significant finding of this work is that combined loading results in intermediate failure modes (Table 3) and intermediate failure loads (Figure 12). The failure loads were well predicted by a quadratic (elliptical) failure model, as described by Equation 1.

An interesting finding was that the maximum joint load (post initial failure) was considerably overpredicted by a quadratic relationship; indicating that there is considerable interaction between the bearing and pull-through damage. This finding has implications for ultimate structural performance prediction, as the pure bearing and pure pull-through tests are anti-conservative. For applications such as crashworthiness, in which the ultimate load and energy absorption of failing joints is vital to predicting the overall structural performance, these findings have particular importance. 


\section{ACKNOWLEDGEMENTS}

The test fixture presented here was designed over the course of a few years and involved a number of student projects. The authors would like to acknowledge Coel Gould and Nurul Mohamad Rosli who made key contributions to the design of the fixture.

\section{REFERENCES}

[1] ASTM, Standard Test Method for Bearing Response of Polymer Matrix Composite Laminates. 2013, ASTM International.

[2] ASTM, Standard test method for measuring the fastener pull-through resistance of a fiberreinforced polymer matrix composite. 2009, ASTM International: West Conshohocken, PA, USA.

[3] Pearce, G., A. Johnson, R. Thomson, and D. Kelly, Experimental investigation of dynamically loaded bolted joints in carbon fibre composite structures. Applied Composite Materials, 2010. 17(3): p. 271-291.

[4] Heimbs, S., S. Schmeer, J. Blaurock, and S. Steeger, Static and dynamic failure behaviour of bolted joints in carbon fibre composites. Composites Part A: Applied Science and Manufacturing, 2013. 47: p. 91-101.

[5] Arcan, M., Z. Hashin, and A. Voloshin, A Method to Produce Uniform Plane Stress States with Applications to Fibre-Reinforced Materials. Experimental Mechanics, 1978. 18(14): p. 141-146.

[6] Yen, S.C., J.N. Craddock, and K.T. Teh, EVALUATION OF A MODIFIED ARCAN FIXTURE FOR THE IN-PLANE SHEAR TEST OF MATERIALS. Experimental Techniques, 1988. 12(12): p. 22-25.

[7] Cognard, J.Y., L. Sohier, and P. Davies, A modified Arcan test to analyze the behavior of composites and their assemblies under out-of-plane loadings. Composites Part A-applied Science And Manufacturing, 2011. 42(1): p. 111-121.

[8] Steeve, B.E. and R.J. Wingate, Aerospace Threaded Fastener Strength in Combined Shear and Tension Loading. 2012, NASA - Marshall Space Flight Centre.

[9] Gould, C. and G.M. Pearce. Intermediate failure of bolted joints in composite materials. in AIAC16: 16th Australian International International Aerospace Congress. 2015. Melbourne, Australia: Engineers Australia. 